\title{
Constructing specialty courses of material forming and control engineering by the advantages of discipline
}

\author{
Lin Chen ${ }^{1, a}$,Wei Ding ${ }^{1, b}$,Qi Fang ${ }^{1, c}$,Yongzhen Liu ${ }^{1, d}$, Zhenliang Li $i^{1, e}$
}

\author{
( ${ }^{1}$ School of Materials \& Metallurgy, Inner Mongolia University of Science \& Technology) \\ achenlin39805@163.com, dingwei@imust.cn, ${ }^{\mathrm{c}}$ fangqi@imust.cn,, liuyongzhen@imust.cn, ${ }^{\mathrm{e}}$ lizhenliang@imust.cn
}

Keywords: Discipline;Materials molding;Major courses

\begin{abstract}
Through curriculum system construction of the material engineering and teaching practice, relying on the advantage of discipline, we pay attention to abilities of getting informations and applying knowledge for students .We will broaden the professional knowledge, pay attention to the systematic and holistic optimization design and focus on comprehensiveness and practice to reflect interdisciplinary integration, update knowledge and construct students reasonable knowledge structure.We try to explore to certification system of higher engineering education professional adapting to this professional and cultivate the students to psychological quality and professional quality of adapting to the work environment in the future.
\end{abstract}

\section{Discipline characteristic and advantage}

Material engineering is first-level discipline that is made of metal pressure processing and metal material heat treatment. Metal pressure processing and metal material heat treatment began to recruit students in 1960 and in 1980, respectively. And master degrees of materials processing engineering and material science majors were obtained in 1996 and 2004. With the adjustment of Classification of Instructional Programs, the names of two majors were changed to material forming and control engineering and metal materials engineering. With several decades of development of materials engineering, we have developed a large number of high-quality professionals and accumulated rich teaching experience and solid scientific research foundation.Teachers and new metal material key laboratory of Inner Mongolia Autonomous Region lay a good foundation for sustainable development of profession.

After years of reform and practice of teaching, material engineering has formed own characteristics in specialty construction and talent cultivation.Namely, facing the demand of economic construction of the whole country and autonomous region, we try to train engineering talents with high quality and strong ability. High level and highly educated teachers have been trained. Senior teacher ratio has reached 69\%, master' s degree or above has reached $85 \%$.This professional focuses on combining teaching with scientific researches. And teachers have taken on a number of state-level scientific research projects and published a large amount of high level scientific research papers. They obtain fruitful research achievements and promote improvement of professional level. Graduates distribute metallurgy and machinery industry all over the country and have been well received by their companies. In recent years, employment rate of undergraduates has reached $90 \%$, the graduation rate of graduate students has reached $15 \%$ to $20 \%$.

\section{The overall goal of the subject construction}

The school's discipline construction will drive discipline construction of material engineering.The total target of material engineering is that we cultivate students with good ideological and political quality and they who are cultivated with computer application and engineering practice ability will have solid basic theories and basic techniques about material science and engineering technology through curriculum system construction and teaching practice of material engineering.

In the process of teaching, we pay attention to train students' ability of obtaining informations and applying knowledge. We broaden professional knowledge and pay attention to optimization 
design of professional integrity and systematicness. This shows integration of a great number of subjects.We try to update knowledge and make students have reasonable knowledge structure to obtain students, psychological quality and professional quality adapting to work environment in the future.

\section{The overall goal and guiding ideology of teaching reform}

Material forming and control engineering professional curriculum reform goal: relying on the discipline advantage, pay attention to the systematic and holistic optimization design professional courses, students build a reasonable knowledge structure, focus on comprehensive and practical, cross and penetration, in order to improve the students' comprehensive professional quality, cultivate students' comprehensive analysis problem, problem-solving ability as the goal.

The dominant idea of this topic teaching reform is based on Ph.D programs to support the subject construction and the key discipline construction project construction of the autonomous region, on the basis of the talents training goal of the 2012 new teaching plan implementation plan, further more, as organization of the teaching activities and engineering education accreditation main basis. Fully embody the characteristics of talent cultivation in our school, whether in the teaching mode, updating teaching content, teaching method and the means require timely new revision of teaching plan, to training to adapt to the social demand of talents with the characteristic of material molding, Lay the foundation for the future of the first batch of "engineering education accreditation" professional construction of Inner Mongolia university of science and technology. Therefore, the professional teaching reform is imperative.

3.1 The guiding ideology of reform: Integrated with practice, focusing on professional characteristics, and establishing an open, research teaching mode

Implementing the 'Features and Excellent'educational philosophy Developing a "good moral character, solid foundation and broaden professional" talent Embody interdisciplinary integration, updating knowledge, broaden students' employment adaptation.

\subsection{The overall objective of the reform}

The professional 2010 undergraduate training program is divided into two research directions, rolling the production and forging production processes. Through professional teaching reform, graduates should possess strong comprehensive analysis of the problem and problem-solving abilities, making it necessary material forming and control of a professional senior technical talent.

\section{The content of the reform}

Update key course teaching content, optimize the teaching plan; strengthen basic skill training, improve the students' ability of practical problems; to strengthen the teaching practice, set up open research-oriented teaching mode, cultivate students' engineering consciousness and thinking ability.

4.1 To broaden professional knowledge, develop thinking skills and basic qualities as a starting point, the establishment of professional knowledge, ability and quality structure

According to the professional basic quality requirements for students, combined with professional features competency requirements, we design the material forming and control engineering professional knowledge ability and quality structure. Strict accordance with the guidelines determined by teaching a variety of comprehensive ability, professional competence and basic quality requirements, Its characterized by the following ideas that: highlight the rolling process technology application ability, reflecting interdisciplinary and comprehensive ability; capacity module settings and capabilities with technical-looking comprehensive; and creative set "material plastic molding engineering", the integration of the basic theory of professional research, optimize the knowledge structure.

\subsection{To optimize and update the teaching contents, to establish opening and research-oriented teaching mode}

In order to precede the opening courses teaching, breaking the bondage of the teaching material is the first thing. At the same time, it can make the teaching material by dominance into auxiliary status; its name should be changed to the teaching reference books, or main teaching reference 
books. Through the network we can collect the latest information and add it to the teaching. First, open teaching must be break through binding of teaching materials, so that the materials change from dominant position as assistant position, and its name should be changed to the reference books for teaching, or primary teaching reference books. Collecting the latest live information added to the teaching course by the network. Second, teaching demonstration tools should convert the blackboard and chalk into computer media, dynamic animation, and the film shown the forming process and the situation of knowledge. Third, teachers are familiar with related international website, and can link at the appropriate time to teach.

Research teaching based on emphasize the scientific principle of forming process is the main characteristic of the teaching mode. To emphasize the presentation of teaching content should be oriented to process, and to show the causes and research process of discipline concept to students guide the students' divergent thinking, stimulate the students' autonomous learning and inquiry motivation, and strengthen students' participation in the construction of knowledge actively and self awareness.

4.2.1 Optimization to update teaching content

(1) Make the classical content more concise.

(2) Make the introduction of new achievements in science and technology content more rich.

4.2.2 The optimization of teaching plan

(1) Employ the heuristic method of teaching, in order to mobilize the initiative, and the enthusiasm of the students.

(2) Develop classroom discussion, in order to culture students learning interest and participation consciousness.

(3) Use multi-media teaching, online Q \& A, in order to make students understand the content of teaching.

(4) Establish the teaching syllabus electronic documents to achieve multimedia, network teaching

4.2.3 To strengthen English skills training and to do excellent course

For the professional degree courses: " Plastic Deformation Theory for Metal " is employed bilingual teaching materials and teaching methods, which enable students not only to learn professional knowledge, but also to learn a foreign language. "Plastic molding of Materials Engineering "," Engineering plasticity theory "," Plastic processing equipment ", "Plastic Material Forming and Control Engineering Foundation" are set to the professional courses. Chinese and English teaching materials and teaching methods at the same time are employed to improve the comprehensive quality of professional in order to implement the "Characteristic and High Quality" education philosophy.

4.3 To strengthen teaching practice, to add course thesis, to cultivate engineering

\section{consciousness and the ability of thinking}

\subsubsection{Update curriculum system training mode}

The cross fusion of two professional direction of reflected the rolling and forging forming divided into Specialized elective course highlight the rolling production characteristics which is the raw materials - production - line of products, which emphasizes on the comprehensive and practical, cross and osmosis. So students have more right to select on their own and can develop their interests and personalities. Professional elective course in total are open 300 class hours (some students who have the energy can also choose). Students are required to learn the full of 200 class hours, and carry on individual development under the guidance of instructors. Optional courses continue widening and deepening knowledge, in order to prepare for specific jobs.

"Plastic Molding of Materials Engineering" course is set to mainly elaborate the basic theory of material deformation, process design and process optimization in machining process. The cross fusion of two professional direction of reflect the rolling, forging forming is the more prominent rolling production characteristics which is the raw materials - production - line of products, which emphasis on the comprehensive and practical, cross and osmosis, optimization and integration of 
teaching content, strengthen students' comprehensive professional skills training, and the ability to solve the students' practical problems.

4.3.2 To combine teaching and research, to strengthen the training of basic skills, improve their ability to solve practical problems

Metal forming engineering science involves rolling and forging. Course teaching is the teaching process of a combination of theory and Practice. The curriculum requires a higher standard of teacher ranks structure and quality. Teachers must have a solid theoretical foundation and professional knowledge in steel rolling and forging. Especially, the teacher who have comprehensive abilities in practice, teaching and scientific research becomes more important. In the course of its construction, the construction of excellent curriculum was an important way to improve teaching quality. In order to adapt to the requirements of University Teachers' own quality, the instructors should not only undertake the task of teaching but also engage in cutting-edge research work. First, we contact MATLAB, ANSYS software tools and dynamic programming method in scientific research, and then apply to teaching. In the CSP sheet rolling process design system, Ingot - Blank - material production process of raw materials and products matching optimization, CAD/CAM optimization design of Continuous casting crystallizer and Optimization of temperature system in the forging process research projects, We continue to realize the deformation theory and process optimization development and application in Engineering. These experiences enable us to maintain the advanced nature of certain teaching. Practice in the teaching and scientific research has taught us that we should not only attend to the teaching task, but also unfold the Frontier research work. It is the basis of advanced teaching. So as to ensure the education adapt the advanced level of discipline development at home and abroad.

4.3.3 Reforming experimental teaching, enhancing the practical ability of students

Experimental teaching is a very important part in teaching. So we create the condition of experiment teaching and enrich the content of experiment. Through the curriculum reform, teaching hours properly reduce at the same time "material forming comprehensive experiment" 32 experimental units is increased. For improving the level of experiment teaching, teachers must participate in the experimental guidance. In order to make the comprehensive experiments instead of demonstration and validation experiments, comprehensive experiment start by the big three second half of the semester and until the four half of the semester.

4.3.4 Computer application and combination of teaching, improving students' scientific research ability

In the process of teaching, we pay attention to the computer into the classroom in the application of material processing. For the students to expand their knowledge, teachers should be combined with scientific research project and teach the new technology and new theory in class.

4.3.5 Reinforcing the teaching practice, adding course thesis, Cultivating engineering consciousness and habit of thinking

We will take 2-3 weeks to establish the curriculum course work. This work will attract students to participate in the project design and practice. The right to practice is provided for our students while the cultivating engineering consciousness and habit of thinking are growing in the student heart.

In teaching practice material molding class of students are arranged for a 2 week course of study time.

\section{Meeting the social requirements, promoting the reform of the teaching of graduates}

\subsection{According to the employment status of students, implementing "order-education" mode}

The school management system is affiliated to the iron and steel industry. The college should take advantage of this relationship and set up the "order-education" mode. Moreover, School aim at market demand and then according to the needs of employers we should perform the teaching reform. It is concluded that implementation of professional settings, course arrangement, teaching content, graduation field work and graduation design and so on. By adjusting the form and method of teaching, enterprise talents who have professional technology, technology and skills are 
cultivated. For example, Forming part of the students of Grade 2000 -2010, according to their place of employment requirements, make a deal with the company. In the graduation internship, Graduates must go to the employing units to do practice. When the graduates go to work, they can enter the occupation environment quickly, adapt to technical requirements and work hard. This kind of order training mode is very welcome by the unit. According to the actual situation of students employment requirements and guide teachers to determine the determination of graduation thesis topic and the proportion of students doing graduation thesis.

\subsection{Method of implementation of the combination of graduation design (Thesis), training and employment}

Previously graduated from the design and method should be replaced by the method of gradually thesis, internship training and employment. The graduation design and graduation thesis links should be combined with the reality of the factory. The graduates should go into the enterprise deeply and do pre-service training. The time of graduation practice can be determined as $3 \sim 4$ weeks, At the same time, according to the training plan of order, the students could complete the half year practice and design tasks in the employing unit. Through this way the enterprises can understand the graduates.

\subsection{Met the needs of society, broaden the channels, expanded the employment field}

With the speeding up of economic and industrial structure adjustment, the employment of college graduates has shown a trend of diversification. To my school graduates, they must start from the grass-roots level and the production line. Survey results show that the main direction of graduates' employment is in production, construction, management first line; the employment is mainly management technology, technology, design and operating personnel line. Through the reform of the curriculum system, we can strengthen the training of basic skills of the students and improve their ability to solve practical problems. Besides, it can also broaden the professional knowledge of students, enhance students' employment ability and expand the employment field.

Through practice, the professional curriculum system of material forming and control engineering is improved and the comprehensive professional quality of students is raised. Engineering practice talents can be trained.

\section{References}

[1] Lin Chen, Jichun Yang, Liping Zhao,Li Combined with the professional characteristics, discuss higher engineering education professional certification effect on professional teaching system[J]. ERMI 2012,08

[2] Wenxue Zhang, The establishment of professional certification system, promoting the reform of Higher Engineering Education[J]. China Higher Education.2008,18:16-18.

[3] Xiuyu Zhao, Lijuan Peng, American higher education programmatic accreditation system to our professional assessment of Enlightenment[J]. Science and Technology Management Research.2007,08:158-159+119. 